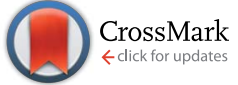

Cite this: RSC Adv., 2017, 7, 8727
Received 22nd November 2016 Accepted 3rd January 2017

DOI: 10.1039/c6ra27177d

www.rsc.org/advances

\section{Influence of epoxidized natural rubber on the phase structure and toughening behavior of biocarbon reinforced nylon 6 biocomposites}

\author{
Emmanuel O. Ogunsona, ${ }^{\text {ab }}$ Manjusri Misra*ab and Amar K. Mohanty ${ }^{\star a b}$
}

\begin{abstract}
Key drivers for automotive material applications require light weight and sustainable materials. This paper reports the engineering properties of hybrid nylon biocomposites as a possible replacement for some currently used filled nylon systems in the automotive industry. Nylon reinforced with 20 wt\% of biocarbon showed tensile and flexural strengths superior to that of neat nylon by 19.5 and $31 \%$ respectively. However, the addition of biocarbon had a detrimental effect on its impact strength and elongation at break. Therefore, epoxidized natural rubber (ENR) was incorporated at low concentrations as an impact modifier due to its compatibility with nylon. An increase in impact strength of $55 \%$ was observed even in the presence of 20 wt\% biocarbon when 7 phr of ENR was incorporated. The encapsulation of some of the biocarbon particles by the ENR increased the absorbance of the impact energy as a result as observed from the morphological analysis of the microstructure of the biocomposites. However, the tensile and flexural strengths showed a relatively marginal decrease due to the presence of ENR at the interface of nylon and biocarbon. Fourier transform infrared spectroscopic (FTIR) analysis revealed possible interactions/compatibility of ENR with nylon and biocarbon.
\end{abstract}

\section{Introduction}

Nylon and its composites are some of the most studied amongst engineering polymers in polymer composite science and engineering. Their applications span a very wide degree depending particularly on their mechanical properties. However, they are very sensitive to notching as cracks start and easily propagate through those notches or stress concentration points during impact. Due to their sensitivity to notching and brittleness, they typically possess poor impact properties. The restriction of the polymer chain by the filler prevents it from plastically deforming and absorbing the impact energy subsequently causing brittle fracture. Several methods to improve the impact strength have been studied. The incorporation of spherical fillers to hinder crack propagation have been explored and observed to improve the impact strength. Another well-established method is the addition of a very low modulus material to the composite; typically the addition of elastomers. This method has been explored by many researchers using different types of elastomers. Modification of these elastomers to improve adhesion with the matrix has also been studied and shown to aid impact strength.

In nylon composites, elastomers such as natural rubber (NR), ethylene propylene diene monomer (EPDM), ethylene

${ }^{a}$ School of Engineering, University of Guelph, Thornbrough Building, Guelph, N1G 2W1, Ontario, Canada. E-mail: mmisra@uoguelph.ca; mohanty@uoguelph.ca ${ }^{b}$ Bioproducts Discovery and Development Center, Department of Plant Agriculture, University of Guelph, Ontario Agriculture College, Guelph, ON, N1G 2W1, Canada propylene rubber (EPR), ${ }^{\mathbf{1 , 2}}$ styrene ethylene butylene styrene (SEBS $)^{1,3}$ just to mention a few have shown improvements in the impact strength but at the cost of a relatively high concentration of the elastomers. It has also been shown that modifying these elastomers with functionalities which can react with nylon end groups can further improve the impact strength by increasing the adhesion between the nylon and elastomer leading to better energy transfer and absorption. Maleic anhydride grafted elastomers (MAH-elastomers) have been used in nylons and shown to be a better impact modifier in comparison to their unmodified counterpart. ${ }^{4}$ Epoxide groups are capable of reacting with the carboxyl, amine and amide groups on the backbone of the nylon chains. Epoxidized natural rubber (ENR) is the derivative of the modification of natural rubber (NR) by the grafting of epoxide groups onto its backbone. Blends of ENR and nylon have been well studied but not as much when used in nylon composites. It was chosen based on the fact that it is a biobased elastomer, highly reactive with nylon and also capable of interacting with the biocarbon used in this work. ENR has shown to form nylon grafted ENR copolymer due to their compatibility. ${ }^{5}$ Several mechanisms have also been proposed for the interaction between nylon and ENR through the interaction of the epoxide group on the ENR with the $\mathrm{COOH}$ and amine groups in the nylon. ${ }^{6,7}$ It has also been suggested that the bond created between these materials are stronger than the individual materials and can lead to increases in the melting temperature of the blends. ${ }^{8}$

The addition of toughening agents such as elastomers to polymer composites materials have typically resulted in the 
separate dispersion of the filler and elastomer in the matrix. It has also resulted in the dispersion of both filler and elastomer within the matrix with interaction between the elastomer and filler as well leading to partial or complete encapsulation of the filler by the elastomer. ${ }^{\mathbf{9 - 1 1}}$ Nylon-ENR based composites using other filler types have also been studied. Nouparvar et al. ${ }^{\mathbf{1 2}}$ characterized nanocomposites made from nylon 6, ENR and organo-modified clay. It was found that by increasing the clay content, the ENR phase within the composite became smaller and more dispersed suggesting that the clay was increasing the viscosity of the nylon phase which in turn caused further dispersion the ENR from increased shearing. However, the maximum impact strength obtained was approximately $5.5 \mathrm{~kJ}$ $\mathrm{m}^{-2}$ at $10 \mathrm{wt} \%$ of ENR within the composite. Beyond that, a decrease was observed. In another study, halloysite nanotubes were used to reinforce nylon 6 with ENR used as toughening agent. ${ }^{13}$ It was observed that the addition of ENR to an already optimized nylon-halloysite composite resulted to a decrease in the tensile and flexural properties but a successive improvement in impact strength with increasing ENR content. At 5 and $20 \mathrm{wt} \%$ ENR loading, the impact strengths were at approximately 5 and $10 \mathrm{~kJ} \mathrm{~m}^{-2}$ respectively in comparison to that of the composite of approximately $25 \mathrm{~kJ} \mathrm{~m}^{-2}$. It was suggested that the interactions between the ENR and nylon and ENR and nanofibers resulted in enhanced impact strengths.

Considering the importance of nylon in various industrial applications, it is therefore necessary to explore new, alternative and bio-renewable resources to curb the use of already diminishing petroleum resources. To the best of our knowledge, the use of biocarbon in conjunction with elastomers and their interactions in nylon composites has never been reported. Biocarbon was chosen because of its advantages similar to those of natural fibers such as its low cost and density, sustainability, renewability and carbon sequestration. ${ }^{\mathbf{1 4}}$ However, it was chosen over natural fibers due to its greater thermal stability and capability of withstanding the high processing temperature of nylon without degradation. ${ }^{15}$ Likewise, it is less hydrophilic than natural fibers; therefore, the concern of hydrolysis of the nylon chains during processing is reduced.

Currently, there are no studies on biocarbon reinforced nylons except for our previously published works. ${ }^{\mathbf{1 6 - 1 8}}$ The first study investigated the effect of biocarbon loading on nylon $6 .^{\mathbf{1 6}}$ It showed that the mechanical properties of the resulting composites were diminished stemming from the inherently defective nature of the biocarbons. In the second study, the effect particle size on the mechanical properties of nylon 6 was investigated. ${ }^{17}$ It was found that by milling the biocarbon over increasing time periods, the particle size reduced. It was also shown that by reducing the particle size, the mechanical properties especially the impact strength was improved. The third study investigated the effect of biocarbon particle size and ranges on the mechanical and thermomechanical properties of nylon $6,10 .^{18}$ It showed that the strengths and moduli of nylon were enhanced when pre-treatment of the biocarbon such as milling was performed. It also showed that by reducing the biocarbon particle size and using a lower particle size range, the impact strength of the biocomposite can be improved and is insignificantly different from the neat nylon. However, in this study, our objectives were to fabricate sustainable hybrid toughened biocomposites from biocarbon reinforced nylon 6 . Knowledge obtained from our previous studies was applied in this study by utilizing the biocarbon particle size range which resulted in maximum strength and stiffness. The novelty in this work was aimed at achieving significantly enhanced impact strength of the biocomposites by utilizing a relatively low concentration of ENR unlike high amounts used in previous studies by encapsulating the biocarbons to reduce rigidity and improve toughness. Typically, to achieve toughening of polymer composites with elastomers, the concentrations have to be as much as 10-20 wt\% and with well dispersed small domains within the matrix. In order to achieve these, mechanical tests were performed such as tensile, flexural and impact analysis, morphological analysis using scanning electron microscopy to observe the composite structure, Fourier transform infrared spectroscopy to determine interactions between the components and differential scanning calorimetry to analyze their thermal properties.

\section{Materials and methods}

\section{Materials}

Nylon 6 (Ultramid B3K) manufactured by BASF was purchased from Entec Polymers, USA. Biocarbon used in this study was produced and supplied by Genesis Industries, CA, USA from Miscanthus fibers obtained from New Energy Farms, Leamington, ON, Canada. The pyrolysis conditions are known to be around $500{ }^{\circ} \mathrm{C}$. The physical, chemical and mechanical properties of this biocarbon have been well characterized in our previously published work and is denoted as "MB". ${ }^{19}$ The work characterized the elemental composition as well as the surface functional groups present on the biocarbon. Results from the analysis showed that it has a CHNO composition of 66.5 2.9, 1.59 and $22.9 \mathrm{wt} \%$ content respectively. FTIR analysis revealed that carboxyl groups are present and significant from the vibration of the carbonyl group peak within the carboxyl group present at $1700 \mathrm{~cm}^{-1}$. The biocarbon particles are heterogeneous in shape and size and therefore the aspect ratio could not be determined nor specified. The epoxidized natural rubber with $25 \mathrm{~mol} \%$ epoxidation, under the trade name of Epoxyprene is a product of Muang Mai Guthrie Public Company Limited of Thailand and supplied by Sanyo Corporation of America. Laboratory grade toluene was purchased and supplied by Sigma Aldrich and was used as a solvent for etching ENR from the fractured surface of the composites.

\section{Composite fabrication process}

The biocarbon was subjected to preprocessing conditions by placing $25 \mathrm{~g}$ of each in a $500 \mathrm{~mL}$ stainless steel ball mill container and milled for $1 \mathrm{~h}$ at $300 \mathrm{rpm}$ using a milling machine (Retsch PM100, Germany). A combination of 65 zirconium dioxide balls and 2 stainless steel balls were used as milling media. The zirconium dioxide balls were $10 \mathrm{~mm}$ in diameter and weighed $3.34 \mathrm{~g}$ each, while the stainless steel balls were 40 
$\mathrm{mm}$ in diameter and weighed $256 \mathrm{~g}$. The milled biocarbon was collected and dried at $105{ }^{\circ} \mathrm{C}$ until constant weight prior to further use.

The ENR was cut into long strips and masticated at $120{ }^{\circ} \mathrm{C}$ and $4 \mathrm{rpm}$ on a two roll mill (Prep-Mill, manufactured by C.W. Brabender Instruments Inc., NJ, USA) to help break down and flatten it into thin sheets of around 1 to $2 \mathrm{~mm}$ in thickness. The sheets were then cut into small pieces approximately $5 \times 5 \mathrm{~mm}$ to be used in the composite fabrication. All three materials were simultaneously compounded in a one-step process. All composites were processed at $250{ }^{\circ} \mathrm{C}$ and at a screw speed of $100 \mathrm{rpm}$ for $120 \mathrm{~s}$ using a HAAKE MiniLab II Micro Compounder (Thermo Scientific, MA, USA) and then injection molded with an injection pressure, injection time, injection back pressure, injection back pressure time and mold temperature of 400 bars, $10 \mathrm{~s}, 150$ bars, $5 \mathrm{~s}$ and $70^{\circ} \mathrm{C}$ respectively using a HAAKE MiniJet Injection molding machine (Thermo Scientific, MA, USA). An illustration of the process is shown in Fig. 1. For simplicity and ease of identification, acronyms have been given to the samples and are listed in Table 1. Preliminary results show that incorporation of ENR below 3 phr has no significant effect on the impact strength of the composite while above $7 \mathrm{phr}$, the strengths and modulus are significantly reduced in comparison to the biocarbon reinforced nylon biocomposite. Therefore, ENR loading between 3 to 7 phr was used. A $20 \mathrm{wt} \%$ loading was chosen for two main reasons based on preliminary studies; above $20 \mathrm{wt} \%$ loading, the wetting of the biocarbon by the nylon is significantly reduced and the viscosity of the composites make it difficult to be injection molded.

Etching of the rubber phase was done by placing the impact fractured surfaces of the composite samples in a test tube with
Table 1 Sample designation and formulation of nylon, biocarbon and ENR composites $^{a}$

\begin{tabular}{llll}
\hline & \multicolumn{2}{l}{ Weight $(\%)$} & \\
\cline { 2 - 3 } Sample designation & Nylon 6 & Biocarbon & ENR (phr) \\
\hline Nylon & 100 & 0 & 0 \\
NB & 80 & 20 & 0 \\
NBE3 & 80 & 20 & 3 \\
NBE5 & 80 & 20 & 5 \\
NBE7 & 80 & 20 & 7
\end{tabular}

${ }^{a} \mathrm{~N}$ - nylon 6, B - biocarbon, E - ENR.

excess toluene. The rubber phase was left to dissolve for $48 \mathrm{~h}$ at room temperature while periodically agitating it to dislodge any rubber from the composites. After dissolving the rubber, the samples were removed, washed with toluene and acetone and then dried in a vacuum oven at $80{ }^{\circ} \mathrm{C}$ for $24 \mathrm{~h}$.

\section{Morphological analysis}

The micrographs of the impact fractured surfaces of the composites were captured and analyzed using a scanning electron microscopy (SEM, FEI Inspect S50, OR, USA). All samples were first sputter gold coated under argon gas for 30 seconds using a Cressington Sputter Coater 108 auto (Cressington Scientific Instruments, UK).

\section{Material interactions}

Possible interactions between the nylon, biocarbon and ENR were analyzed through a Fourier transform infrared

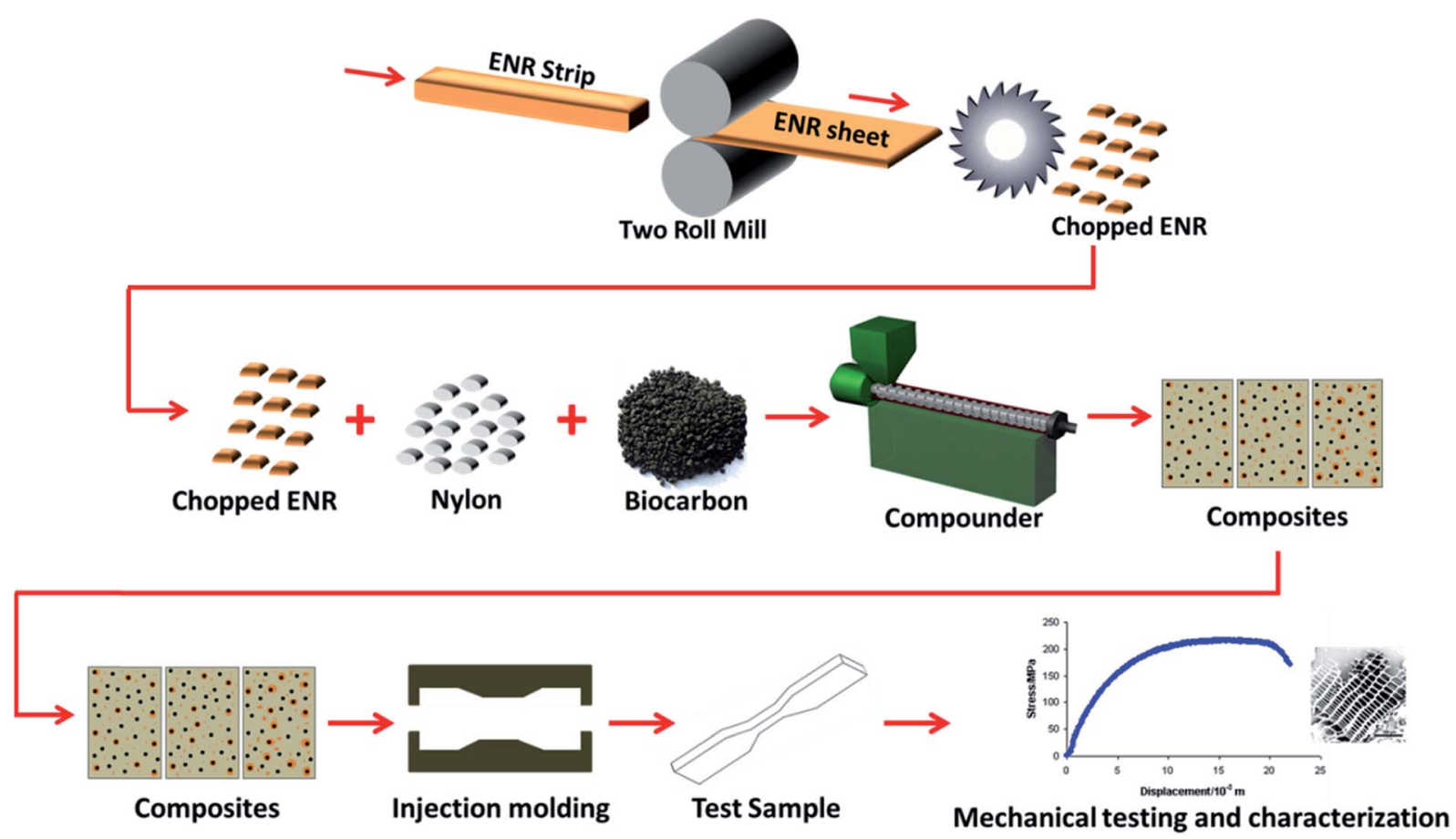

Fig. 1 Preparation, processing and fabrication of hybrid nylon/biocarbon/ENR biocomposite. 
spectroscopy (FTIR) Thermo Scientific, Nicolet 6700. A total of 32 scans, between a transmittance range of 4000 and $400 \mathrm{~cm}^{-1}$ and at a resolution of $4 \mathrm{~cm}^{-1}$ were collected for each of the aforementioned samples. Samples were prepared by grinding the composites to particles less than $1 \mathrm{~mm}$ in size to expose and disperse the interfaces in the composites.

\section{Thermal analysis}

Thermal behaviors and transitions of the neat and composite materials were examined by differential scanning calorimeter (DSC Q200), manufactured by TA Instruments, USA under nitrogen flow at a rate of $50 \mathrm{~mL} \mathrm{~min}^{-1}$. Flat pieces removed from the same parts of the molded samples ranging between 5 to $10 \mathrm{mg}$ in weight were placed in an aluminum pan and heated from 0 to $250{ }^{\circ} \mathrm{C}$ at a rate of $10{ }^{\circ} \mathrm{C} \mathrm{min}{ }^{-1}$, held at $250{ }^{\circ} \mathrm{C}$ for $5 \mathrm{~min}$, cooled to $0{ }^{\circ} \mathrm{C}$ at a rate of $5{ }^{\circ} \mathrm{C} \min ^{-1}$, held at $0{ }^{\circ} \mathrm{C}$ for $5 \mathrm{~min}$ and then scanned again to $250{ }^{\circ} \mathrm{C}$ at the rate of $10{ }^{\circ} \mathrm{C}$ $\min ^{-1}$. The melting temperature $\left(T_{\mathrm{m}}\right)$, crystallization temperature $\left(T_{\mathrm{c}}\right)$, crystallization enthalpy $\left(\Delta H_{\mathrm{c}}\right)$ and melt enthalpy $\left(\Delta H_{\mathrm{m}}\right)$ were determined from these scans. The first heating cycle was discarded as it was used to remove the thermal history of the samples.

The possible miscibility and interactions occurring within the composites were investigated by studying the viscoelastic behavior of the samples using a Dynamic Mechanical Analyzer (TA Instruments) in dual cantilever mode with a frequency of $1 \mathrm{~Hz}$ and a strain amplitude of $25 \mu \mathrm{m}$. Testing was done within a temperature range of -80 to $150{ }^{\circ} \mathrm{C}$ with a ramp rate of $3{ }^{\circ} \mathrm{C}$ $\min ^{-1}$ and a pre-load of $1 \mathrm{~N}$. Samples with an approximate width and thickness of $12.6 \mathrm{~mm}$ and $3.35 \mathrm{~mm}$ were used.

\section{Water absorption}

Water uptake of the samples was performed in accordance with ASTM D570 for water absorption of plastics. Injection molded disc shaped coupons with a diameter and thickness of $25 \mathrm{~mm}$ and $15 \mathrm{~mm}$ respectively were used. Three replicates per sample were used and dried to constant weight prior to testing. Samples were placed in room temperature deionized water bath at the same depth with the water level, and the level was kept constant to prevent pressure changes. Each sample was weighed every $24 \mathrm{~h}$ using a precision weigh balance with a precision of $0.0001 \mathrm{mg}$. The water uptake was calculated using eqn (1):

$$
\text { Water uptake }(\%)=\frac{W_{1}-W_{0}}{W_{0}} \times 100 \%
$$

with $W_{1}$ and $W_{0}$ as the wet and dry weight of the composites respectively.

\section{Mechanical properties}

All samples were conditioned at $23 \pm 2{ }^{\circ} \mathrm{C}$ and $50 \pm 5 \%$ relative humidity for a period of $40 \mathrm{~h}$ before any test was done. Tensile properties were measured using samples prepared according to Type V specimen of ASTM standard D638. Flexural properties were measured using samples prepared according to procedure B of ASTM standard D790. The tensile and flexural tests were conducted on a Universal Testing Machine (Instron, Norwood, MA, USA).

Impact strengths of the samples were measured using samples prepared in accordance to ASTM standard D256 with sample notch depths of $2 \mathrm{~mm}$ made using a TMI Notching Cutter. The tests were conducted on a TMI Monitor Impact Tester (Testing Machines Inc., DE, USA).

\section{Results and discussion}

\section{Interactions between components of hybrid composites}

Nylon-ENR interactions. The IR spectroscopy was used to determine interactions between nylon, biocarbon and ENR. Spectra of nylon, NB and NBE7 were analyzed in Fig. 2. To magnify the interactions between components, a separate blend of nylon with 15 phr of ENR and ENR with $10 \mathrm{wt} \%$ of biocarbon was fabricated using the same processing conditions as other samples and analyzed as well in Fig. 2. This blend and ENRbiocarbon composite were used to analyze the interactions between nylon and ENR because at the low concentrations of ENR used in the composites, the interactions are not easily detected by FTIR. Therefore, separate samples were made to magnify the interactions between individual components. There is a new peak at $1735 \mathrm{~cm}^{-1}$ in the nylon-ENR blend and barely observable in NBE7 (Fig. 2). This peak corresponds to the $\mathrm{C}=\mathrm{O}$ vibration from the formation of ester groups. Ester groups are formed in the blend from the esterification reaction between epoxide groups (1248 and $880 \mathrm{~cm}^{-1}$ ) in the ENR and $\mathrm{COOH}$ end groups $\left(1650 \mathrm{~cm}^{-1}\right)$ in nylon (carboxylic acid linkage) as shown in the schematic representation in Fig. 5 . The peak at $3300 \mathrm{~cm}^{-1}$ of the nylon-ENR blend is representative of the $\mathrm{N}-\mathrm{H}$ vibration of the amide group in nylon. This peak widens and forms a huge shoulder when compared to that of neat nylon. Also, an increase in the intensity is observed but not dominant in NBE7. This is due to the formation of hydroxyl groups from the formation of esters which vibrate around 3200 to $3400 \mathrm{~cm}^{-1}$, therefore overlapping with the $\mathrm{N}-\mathrm{H}$ bonds. It could also be due to the increase in the number of $\mathrm{N}-\mathrm{H}$ bonds formed from the interaction between the epoxide group in ENR and the amine end groups in nylon (amine linkage) as shown in Fig. 5. This would therefore imply an increase in the amount of nitros groups ( $\mathrm{N}-$ O) in the nylon and should be observed through changes in the $\mathrm{N}-\mathrm{O}$ peaks at 1370 and $1540 \mathrm{~cm}^{-1}$. It can be observed that the intensities are significantly increased as compared to that of neat nylon and NBE7. The peak at $1420 \mathrm{~cm}^{-1}$ was elaborated in the nylon-ENR blend whereas not as much in neither nylon nor the composites. This peak corresponds to the vibration of $\mathrm{C}-\mathrm{H}$ bonds and is exaggerated due to the vibration of the same bonds also present in the ENR structure. The presence of the $\mathrm{C}=\mathrm{O}$ peak, the increase in intensity of the $\mathrm{N}-\mathrm{O}$ peaks and broadening of the amide group at $3300 \mathrm{~cm}^{-1}$ suggests the interaction of ENR with nylon through amine and carboxylic acid linkages. Xie et al. ${ }^{5}$ suggested that blends of ENR and nylon form a graft copolymer (ENR-g-nylon) due to the interactions between the epoxide groups in the ENR and functional groups in nylon. There is good agreement between results found in this study and those by Xie et al. The changes in the spectra of the 


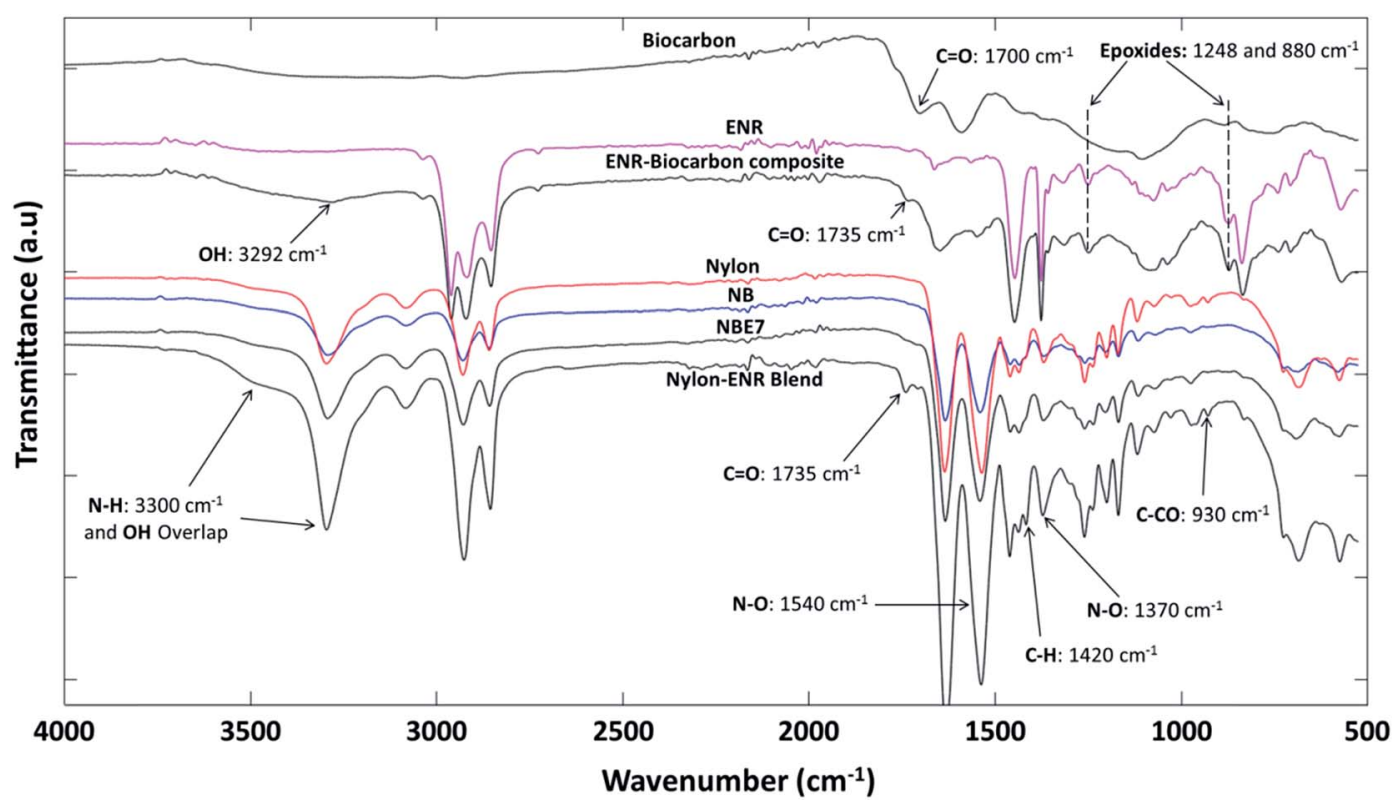

Fig. 2 FTIR spectra (from top to bottom) of: biocarbon, ENR, ENR/biocarbon composite, nylon, NB, NBE7 and nylon/ENR blend.

nylon-ENR blend which are not observed in that of NBE7 when compared to nylon can be attributed to the low concentrations of ENR and therefore fewer interactions between the epoxide groups in ENR with nylon. For these reasons, the ENR-biocarbon and nylon-ENR blends were made.

ENR-biocarbon interactions. Interaction between the ENR and biocarbon is represented in the FTIR spectrum of ENR- biocarbon composite in Fig. 2. It can be observed around 3292 $\mathrm{cm}^{-1}$ that there is a wide but visible peak. This peak can be attributed to the formation of hydroxyl groups from the plausible reaction between the $\mathrm{COOH}$ groups on the biocarbon surface and the epoxide groups on the ENR. The presence of hydroxyl groups in the form of phenols on the biocarbon is possible due to the very large and broad peak around 3000 to
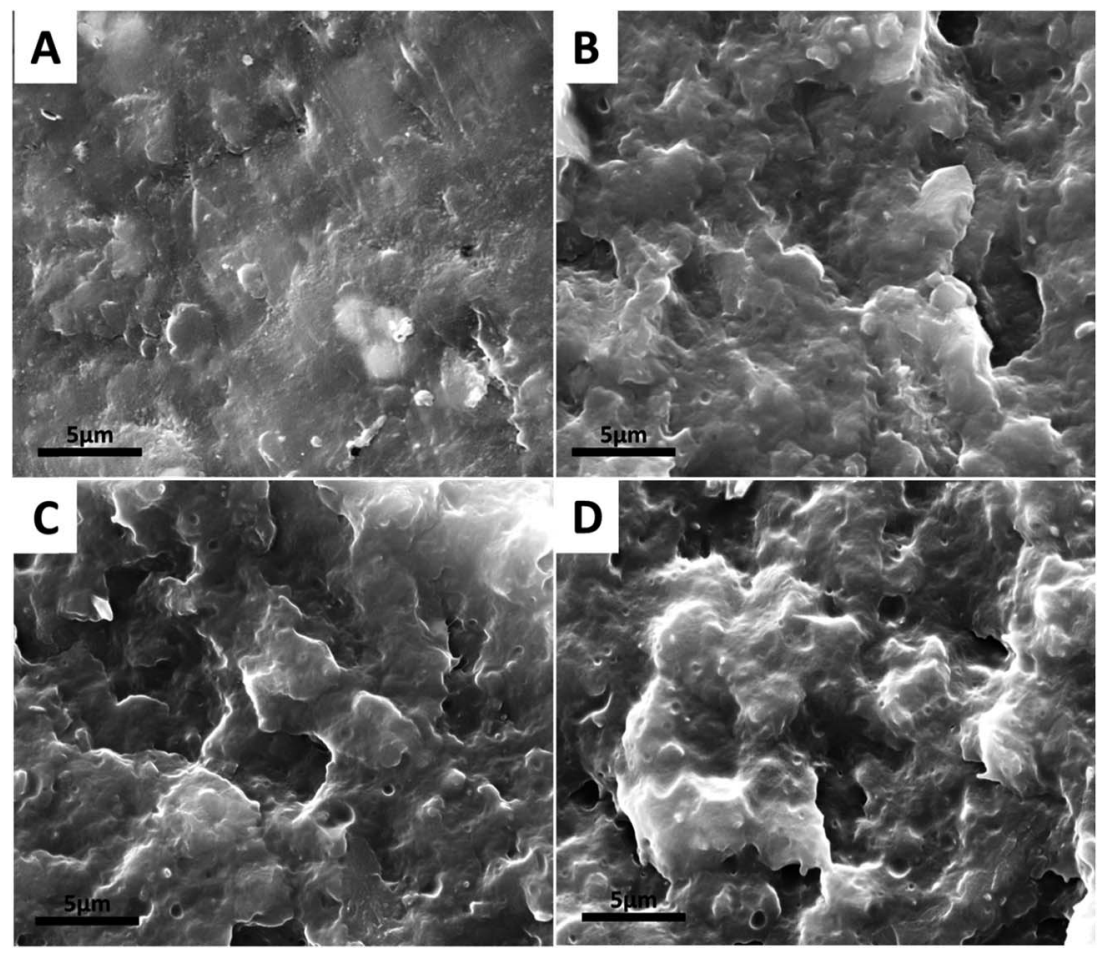

Fig. 3 Micrographs of impact fractured surfaces of neat nylon (A), NBE3 (B), NBE5 (C) and (D) NBE7. 
$3500 \mathrm{~cm}^{-1}$. This can also react with the epoxide groups. However, from the FTIR of the biocarbon, it's clear that the $\mathrm{COOH}$ groups are prevalent and therefore make up most of the interactions. The epoxide groups scission to substitute the hydrogen on the carboxylic groups to form an ester while creating a hydroxyl group. The presence of the epoxide groups in the FTIR of the ENR-biocarbon composite indicates that not all epoxide groups were reacted during this reaction. It also suggests that the amount of $\mathrm{COOH}$ groups present on the biocarbon is limited and not sufficient enough to react with all epoxide groups. A study of the interactions of ENR with carbon black was done by Manna et al. ${ }^{20}$ Carbon black was oxidized to form oxygen containing groups such as $\mathrm{COOH}$ on its surface. Both unoxidized and oxidized carbon black were compounded separately with ENR. It was found through infrared spectral studies that the composite with oxidized carbon black led to chemical bond formation; formation of ester and phenolic ether type bonds while that of the unoxidized carbon black did not. This correlates well with the interaction found between the ENR and biocarbon. Therefore, it can be inferred that the good interaction between the three-component system will possibly result in efficient (1) transfer of stress from either ENR or nylon to biocarbon and (2) transfer and dissipation of impact energy from nylon to ENR, subsequently resulting to improved impact strength.

\section{Morphological analysis}

The micrograph of the impact fractured surfaces of all the composites are shown in Fig. 3. It can be observed that the surface of NB is relatively flat which is indicative and typical of a brittle fracture. It can also be observed that the biocarbons are well embedded in the matrix and to some degree visible but have a layer of matrix covering them. No voids or gaps can be observed at the interface between the biocarbon and nylon. The absence of voids and presence of a layer of matrix on the biocarbon suggests that the fracture propagated through the matrix and therefore having good adhesion to the biocarbon. ${ }^{21}$ With the addition of ENR (NBE3), the fracture surface is seen to be irregular with a rough topology. It is even more difficult to distinguish between the nylon, ENR and biocarbon. This is due the ENR acting as an interphase between the nylon and biocarbon partially encapsulating the biocarbon while in some cases, completely encapsulating it. This results to a thicker layer on the biocarbon surface making it difficult to visually identify it. It also corroborates with the results from the tensile and impact strengths, discussed in mechanical properties section.

Upon further addition of ENR (NBE5 and NBE7) the fractured surfaces become more uneven and the distinction between biocarbon particles and matrix is equally difficult. This is due to the same effect as observed in NBE3 but with more biocarbons being encapsulated with thicker layers of ENR. Evidence of the encapsulation of biocarbon by ENR and fracture of the ENR containing composite through the ENR phase is given in Fig. 4.

In Fig. 4, micrographs of the impact fractured surfaces of composites containing ENR after etching with toluene to remove the rubber phase are presented. In NBE3, it can be observed that well distributed and relatively uniform voids are present within the matrix. This suggests that the ENR is well dispersed in the matrix and not forming large island phases. It can also be observed that the biocarbons are now visible and are lodged in some of the voids. The visibility of the biocarbons and presence of gaps around the biocarbons after etching out ENR show that the ENR encapsulated the biocarbon and acted as an interphase between the biocarbon and nylon. Similar trend is

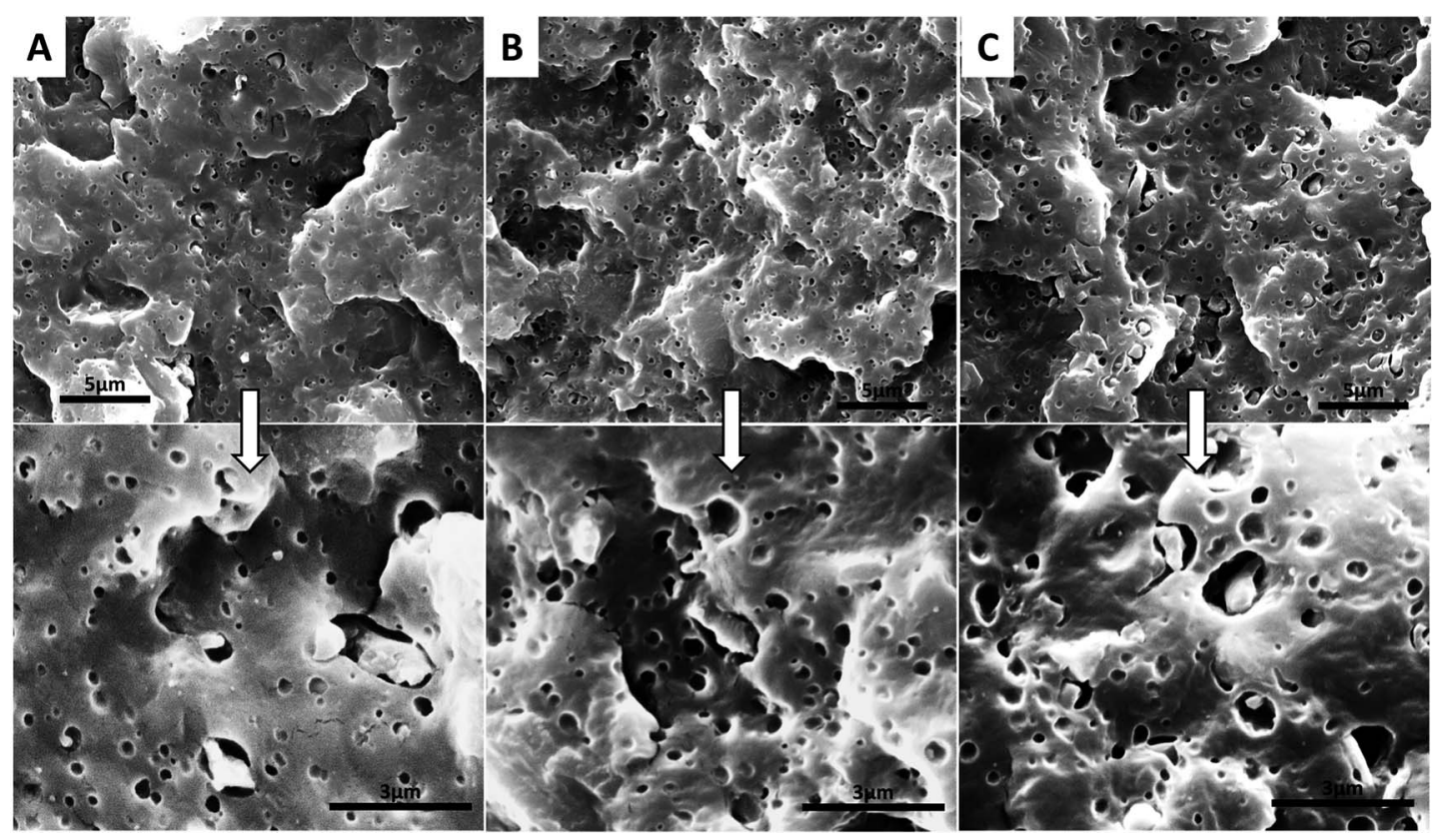

Fig. 4 Micrographs of etched impact fractured surfaces of NBE3 (A), NBE5 (B) and (C) NBE7 (lower roll are magnification of upper images, 11511 to 30000 times). 


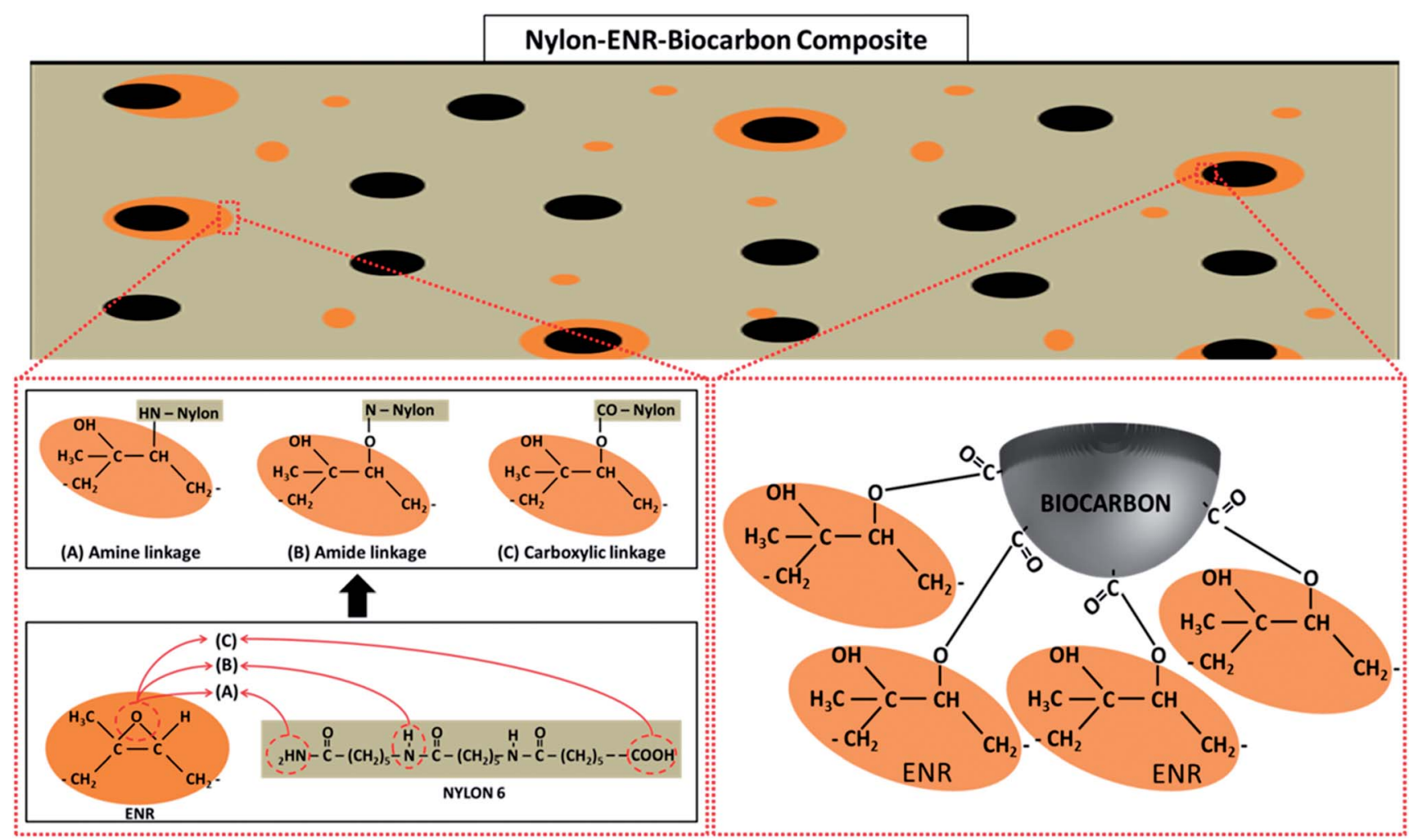

Fig. 5 Representation of plausible interactions between nylon, biocarbon and ENR.

observed with further increase in ENR concentration; encapsulation of the biocarbons and a well dispersed rubber phase within the matrix is observed. However, it is noticed that the voids in the nylon are larger in size while the gaps between the nylon and biocarbon is thicker. Wider gaps indicate that a thicker layer of ENR was encapsulating the biocarbon particles while larger and irregularly shaped voids could indicate the removal of biocarbon particles which have no adhesion to the nylon after etching out of the ENR.

In summary, the presence of epoxide groups on the rubber makes it reactive with both nylon and the biocarbons and therefore drives it to their interface. The epoxide group can react with the nylon through carboxylic acid and amine end group linkages ${ }^{12,22}$ while also reacting with the $\mathrm{COOH}$ groups on the biocarbons. Similar results were observed by Hornsby et al. ${ }^{11}$ where rubber encapsulated glass beads were seen in polypropylene/rubber/glass beads composites when maleic anhydride grafted ethylene propylene rubber (MA-EPR) was used. Complete separation of the phases, with no interaction was observed when un-functionalized ethylene propylene rubber was used. Encapsulation of the glass beads by the MAEPR was due to the reaction between the $\mathrm{OH}$ groups and maleic anhydride therefore driving it to the interface between the polypropylene and glass beads.

\section{Thermal analysis}

Effect of ENR on the nylon phase. The melt behavior (Fig. 6) reveal that neat nylon and its composites display two melting peaks; low and high intensity peaks at $215{ }^{\circ} \mathrm{C}$ and $220{ }^{\circ} \mathrm{C}$ respectively. Studies of nylon 6/clay composites have shown that the small melting peak corresponds to the formation of $\gamma$-form crystalline structures while the high temperature peak corresponds to the $\alpha$-form crystalline structure..$^{23,24}$ The $\gamma$-form crystalline phase is considered an imperfect crystal formation with hydrogen bonding formed between parallel chains while the $\alpha$ form crystalline phase is more stable with hydrogen bonds formed in-between anti-parallel chains which increases the packing of the chains (crystallinity). ${ }^{25}$ This double melting peak

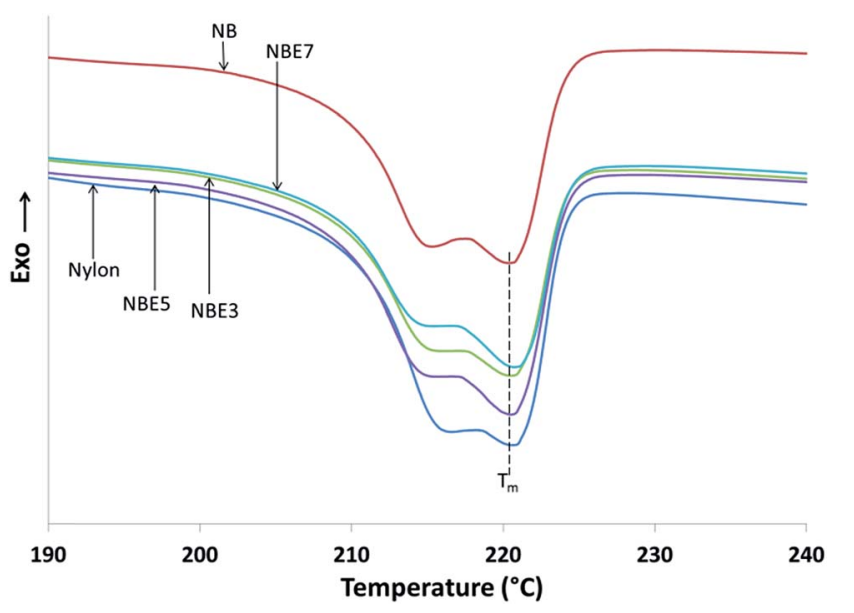

Fig. 6 DSC heating cycle of nylon and the composites. 
phenomenon has been described in literature as the perfection of crystals during melting where poor crystal formation improves during melting to a more perfect crystal formation. ${ }^{26}$ It should also be noted that the smaller peak in NB is marginally more pronounced than that of the neat nylon. This is as a result of the biocarbon further preventing the formation of more perfect crystallites in the nylon by restricting mobility. This causes the formation of more imperfect crystallites and translates to a more pronounced peak. With the addition of ENR to the composite (NBE3, NBE5 and NBE7), it can be noticed that the small peaks become less pronounced and broadened and looking more like a shoulder. The difference between NB and NBE3, 5 and 7 is the presence of epoxidized natural rubber. Therefore, this suggests that the encapsulating effects of the ENR on the biocarbons and in the nylon phase are reducing the formation of imperfect crystallites. It is possible that the previous, allows for better mobility of the nylon chains and therefore reducing imperfect crystal formation. However, there is no change in the main peak which is the melting temperature, unlike shifts to a higher temperatures reported by Nouparvar et $a .^{8}$ This difference could be as a result of the difference in ENR concentration used in this study versus 10 wt $\%$ used in the study by Nouparvar.

The cooling cycle of nylon and its composites are shown in Fig. 7. Table 3 summarizes the thermal attributes of all the samples. The melt crystallization curves of the composites compared to neat nylon is observed to shift to a lower temperature indicating that there is restriction of the nylon chains from crystallizing. The addition of biocarbon to nylon (NB) reduces the temperature from $192.7^{\circ} \mathrm{C}$ to $189.8^{\circ} \mathrm{C}$ implying that biocarbon restricts the mobility and therefore hindering crystal formation. When NBE3, NBE5 and NBE7 are observed, it can be noticed that the melt crystallization temperatures remains mostly the same as NB with no trend, indicating no effect on enhancing or retarding nucleation of crystals.

The viscoelastic behavior of the composites compared to neat nylon is represented in Fig. 8 and Table 2. The slight vibrations of the long molecular chains of the amorphous phase in nylon as detected by DMA was used to determine the $T_{\mathrm{g}}$ of

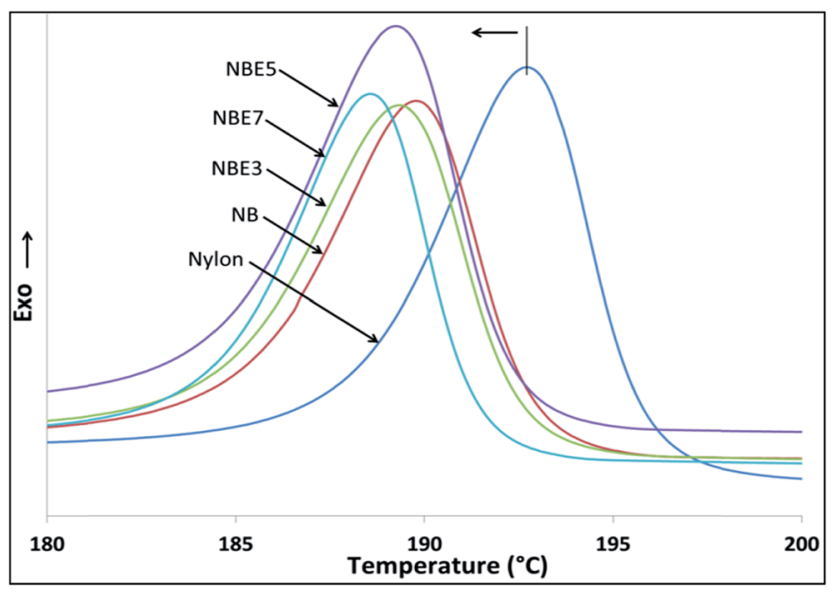

Fig. 7 DSC cooling cycle of nylon and the composites. both the nylon and ENR phases and also to observe any possible effect they have on each other. Two distinct sets of peaks can be observed; a set between $-40{ }^{\circ} \mathrm{C}$ and $-20{ }^{\circ} \mathrm{C}$ and another between $55^{\circ} \mathrm{C}$ and $75^{\circ} \mathrm{C}$ representing the $T_{\mathrm{g}}$ of ENR and nylon respectively. The nylon peak is at approximately $64{ }^{\circ} \mathrm{C}$ as determined from the tan delta curve apex. When biocarbon is added to nylon (NB), the intensity of the peak is reduced and a shift to a lower temperature of $60^{\circ} \mathrm{C}$ is observed. Reduction in the intensity is due to the restricting effect of biocarbon on the nylon chains thereby reducing its ability to absorb energy. Addition of ENR to the composite (NBE3) shows an increase in the peak intensity and a shift to a higher temperature of $70.58{ }^{\circ} \mathrm{C}$ when compared to NB. Further increase of ENR shows no significant changes to the peak with the $T_{\mathrm{g}}$ remaining mostly the same. This behavior could be due to two mechanisms; encapsulation of the biocarbon and the formation ENR-g-nylon at the ENR-nylon interface. Encapsulation of some the biocarbon particles increases the ability of the nylon to absorb energy as it acts like a particle with a stiff core but rubbery outer layer. The formation of ENR-g-nylon has been reported in literature to be more thermally stable than both nylon or ENR and also stronger with higher flow resistance in the molten state. $^{27}$ Therefore, the presence of a more thermally stable, stronger and flow resistant material grafted to nylon chains can cause a shift of the $T_{\mathrm{g}}$ to a higher temperature. Nouparvar et al. ${ }^{\mathbf{8}}$ studied the thermal properties of nylon 6 and ENR blend composites with clay and found that the formation of ENR- $g$ nylon at the interface led to improved melting temperature of the nylon due to its higher thermal stability. A progressive shoulder shift or onset away from NB to higher temperatures can also be observed in NBE3, NBE5 and NBE7. This shows that the chains require more energy or heat to cause vibration and motion possibly due to the ENR-g-nylon.

Effect of nylon on the ENR phase. The $T_{\mathrm{g}}$ and peak intensities of the ENR phase can also be observed to increase with

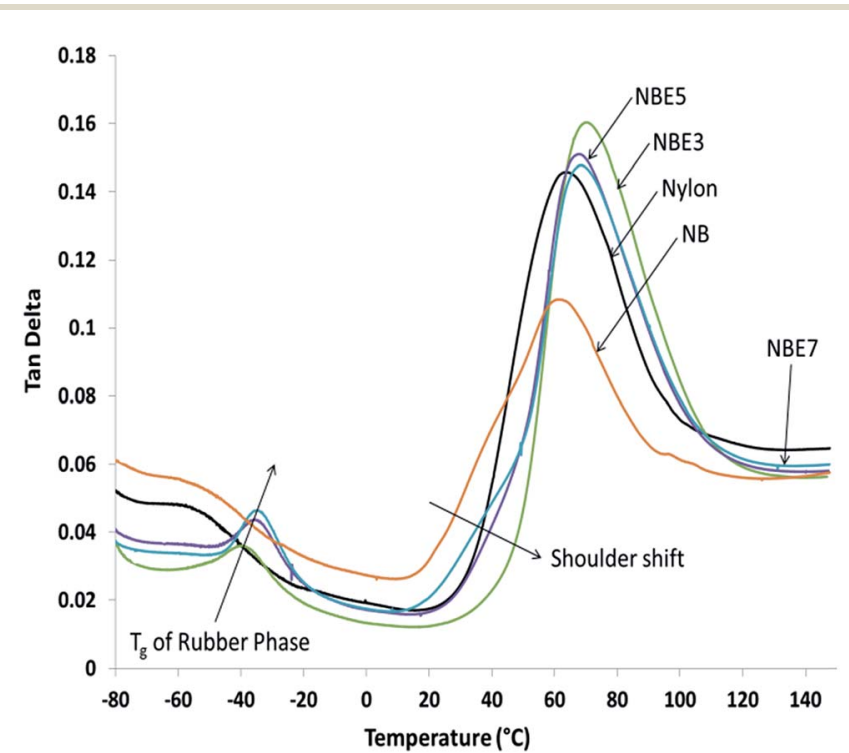

Fig. 8 DMA graph showing the tan delta peaks of PA6 and its composites. 
Table 2 DSC and DMA data of nylon and its composites

\begin{tabular}{|c|c|c|c|c|c|c|}
\hline Samples & $T_{\mathrm{c}}\left({ }^{\circ} \mathrm{C}\right)$ & $\Delta H_{\mathrm{c}}\left(\mathrm{J} \mathrm{g}^{-1}\right)$ & $T_{\mathrm{m}}\left({ }^{\circ} \mathrm{C}\right)$ & $\Delta H_{\mathrm{m}}\left(\mathrm{J} \mathrm{g}^{-1}\right)$ & $T_{\mathrm{g}, \text { DMA-nylon }}\left({ }^{\circ} \mathrm{C}\right)$ & $T_{\mathrm{g}, \text { DMA-rubber }}\left({ }^{\circ} \mathrm{C}\right)$ \\
\hline Nylon & 192.7 & 69.29 & 220.63 & 55.66 & $65.49(2.41)$ & - \\
\hline NB & 189.77 & 48.99 & 220.44 & 40.33 & $60.24(1.42)$ & 一 \\
\hline NBE3 & 189.93 & 47.57 & 221.08 & 44.43 & $70.58(0.61)$ & $-39.43(0.24)$ \\
\hline NBE5 & 188.19 & 44.72 & 220.86 & 44.61 & $69.85(2.93)$ & $-35.95(0.59)$ \\
\hline NBE7 & 188.56 & 47.42 & 220.74 & 43.39 & $69.36(1.23)$ & $-35.39(0.45)$ \\
\hline
\end{tabular}

subsequent increase in ENR concentration. The presence of ENR dispersed within nylon and at the interphase of nylon and biocarbon results in the formation of more ENR-g-nylon restricting the rubber chains at the local regions of the interfaces. These lead to the increase in $T_{\mathrm{g}}$ of the rubber. The shifts in the peaks of both nylon and ENR phases to higher temperatures indicates some miscibility. ${ }^{28}$ The results from the thermal analysis suggest that at the ENR concentrations used herein, it causes some chain restriction in the nylon amorphous phase but does not after the crystalline phase as observed from the broadening of the smaller peaks of NBE3, 5 and 7.

\section{Mechanical properties}

Tensile properties. The tensile strengths and moduli of the composites are represented in Fig. 9. Addition of biocarbon to nylon 6 resulted in an increase in both strength and modulus. This increase can be attributed to the presence of good interaction between the biocarbon and nylon as seen from the wetting of the biocarbon with nylon (Fig. 3). During tensile strain, stress transfer from the nylon to the biocarbon is efficient stemming from the good interface and therefore results to improvement in the tensile strength. In a previous work, the tensile strength was observed to increase when biocarbon was used to reinforce nylon 6,10 . It was shown that there was good wetting of the biocarbon with the nylon resulting to improvements in the tensile strength. ${ }^{18}$ In a study, bamboo charcoal powder was used to reinforce polyethylene at various concentrations. ${ }^{29}$ It was found that the tensile strength was more than double that of neat polyethylene at $60 \%$ wt filler loading. Further increases were observed at 70 and $80 \%$ wt loadings. These results were attributed to the good interface between the charcoal and polyethylene. The effect of bamboo charcoal on the mechanical properties of wood-polyethylene composites was also studied. ${ }^{30}$ The subsequent addition of charcoal to the composites showed improvements in the tensile strengths of the composites. It was suggested that the presence of charcoal decreased the deformation of the polymer matrix in the elastic zone and therefore resulted to strength improvement. The addition of ENR to the composite system (NBE3) drastically decreases the strength even below that of neat nylon. This is as a result of the ENR acting as an interface and encapsulating the biocarbon particles. Though, there is good adhesion between the biocarbon-ENR and ENR-nylon as observed in Fig. 3, the inferior strength of the ENR acts as the weakest link in a chain and therefore fracture occurs at the ENR phase. As a result, there is a discontinuity in transfer of stress from the nylon to the biocarbon terminated at the ENR interface. With the further addition of ENR (NBE5 and NBE7), the tensile strength is observed to decrease further. This is due to the same mechanism occurring in NBE3 but with more ENR phases dispersed within the composite and the encapsulation of more biocarbon particles as observed in Fig. 4. Hornsby et al. studied the

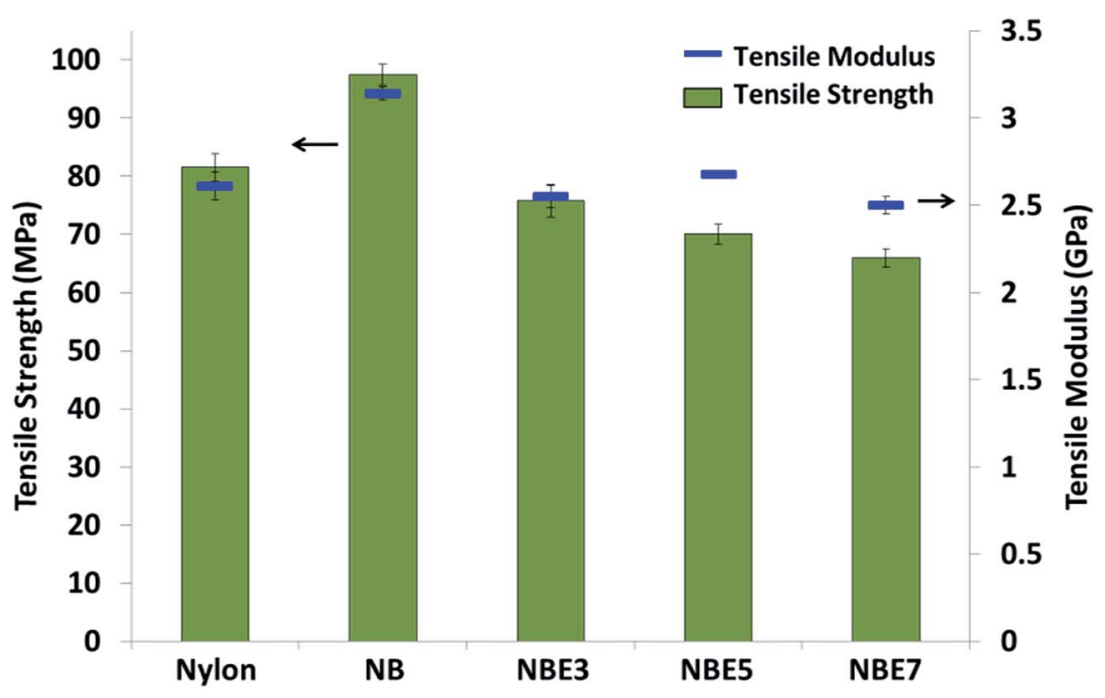

Fig. 9 Tensile strength and modulus of nylon 6 and composites. 
mechanical properties of polyethylene based ternary phase consisting of ethylene propylene rubber (EPR) and glass beads as reinforcements. ${ }^{11}$ They found a similar result when the glass beads were encapsulated with maleic anhydride grafted EPR within the polypropylene matrix. Reduction in tensile strength was as a result of the inferior EPR interface between the glass beads and polypropylene phase.

The tensile moduli of the composites also follow the same trend as the strength. There is an initial increase with the addition of biocarbon (NB) and then a decrease with the addition of ENR and subsequent addition thereafter (NBE3, NBE5 and NBE7). Addition of stiff filler to a polymer typically causes the modulus to increase as the filler acts to restrict the polymer chains. In our previous study, addition of biocarbon to nylon 6 , 10 resulted in improvements in the moduli of the composites. ${ }^{18}$ Polycaprolactone filled with carbonized lignin particles also exhibited an increase in the composite modulus. ${ }^{31}$ ENR has a very low modulus; inferior to that of nylon and biocarbon and therefore decrease the modulus of the composites with increasing concentration as it is dispersed in the nylon. The sharp decrease noticed from NB to NBE3 can be attributed to the encapsulation of the biocarbon with ENR. A change in the phase structure from biocarbon-nylon to ENR-nylon interfaces prevents the biocarbon from restricting the mobility of nylon chains but acting as an elastic particle with a hard core. In the same work by Hornsby et al., comparable results were observed in the modulus. There was a decrease resulting from the rubber encapsulation of the glass beads.

Flexural properties. Just like the tensile properties, the flexural properties follow the same trend; an initial increase in the strength and modulus with the addition of biocarbon and then successive decrease thereafter with the addition of and increasing content of ENR as observed (Fig. 10). Deformation mechanisms occurring during flexural test are through tensile and compressive forces. The flexural property is a combination of the stress in tension mode of one surface of the test specimen while stress in compression of the other surface in compression mode. In tension mode, the stress from the nylon phase can easily be transferred to the biocarbon from good wetting

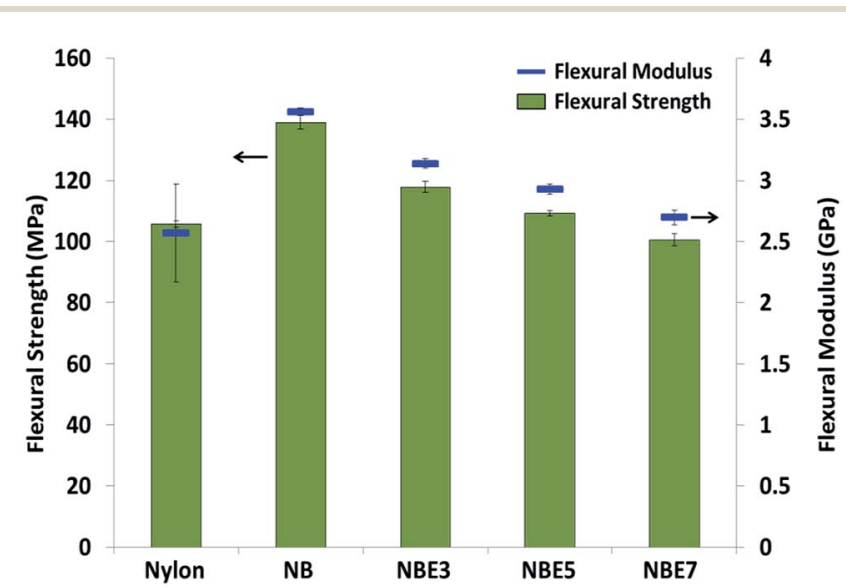

Fig. 10 Flexural strength and modulus of nylon and its hybrid composites. property while in compression mode, the biocarbon acts to restrict the nylon chains from deformation. This combination results to a significant increase of 31 and $39 \%$ in flexural strength and modulus in NB when compared to neat nylon respectively. ENR incorporation results to decrease in these properties. With ENR at the interface of biocarbon and nylon and also dispersed in the nylon, deformation is increased as the ENR plastically yields easily preventing the biocarbons from restricting chain mobility of the nylon in the compression mode. In the tension mode, the ENR acts the same way as in the tensile strength test.

Impact properties. Nylon has relatively good impact strength when compared to other polymers in the same category. However, addition of fillers to further improve its tensile and flexural properties usually results to a decrease in impact strength. A similar result is observed when biocarbon is added to the nylon (NB); a decrease is observed (Fig. 11). This is due to the restriction of the polymer chains to plastically deform and absorb energy when impacted. As observed and stated from the morphological analysis, a layer of nylon is seen to cover the biocarbon therefore showing good adhesion between both materials. Addition of ENR to NB with increasing concentrations subsequently results to increase in impact strength. In NBE3, it can be seen that the impact strength is improved when compared to NB and neat nylon. This improvement is as a result of the encapsulating effect of the ENR on the biocarbon and also being well dispersed in the nylon phase. The significantly lower modulus of ENR than nylon and biocarbon makes it an effective impact modifier through plastically deforming and absorb energy by concentrating the stress around the dispersed phases in the nylon. ${ }^{32,33}$ Elongation of composites has always been problematic. Addition of fillers typically reduces this property by several folds depending on the concentration of the filler used. In this study, addition of biocarbon is also seen to reduce the elongation at break by 12 folds. The biocarbons restrict the chains from moving and causes early and brittle fracture. The elasticity of ENR or ability to elongate several times its length is beneficial in these composites. It can be observed in all the composites containing

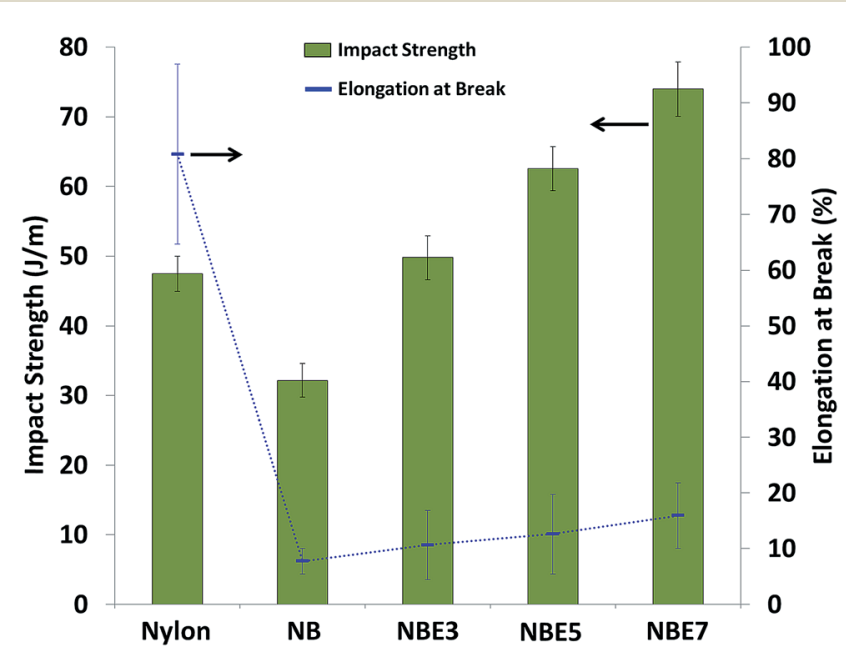

Fig. 11 Impact strength and elongation of nylon 6 and its composites. 
Table 3 Comparison between biocarbon reinforced nylon 6 biocomposites and commercially available mineral filled nylon 6 composite

\begin{tabular}{|c|c|c|c|c|c|}
\hline Properties & Unit & $\begin{array}{l}20 \mathrm{wt} \% \text { biocarbon } \\
\text { filled nylon } 6^{a}\end{array}$ & $\begin{array}{l}20 \mathrm{wt} \% \text { biocarbon }+3 \mathrm{phr} \\
\text { ENR filled nylon } 6^{b}\end{array}$ & $\begin{array}{l}20 \mathrm{wt} \% \text { mineral } \\
\text { filled nylon } 6^{c}\end{array}$ & $\begin{array}{l}20 \mathrm{wt} \% \text { natural fiber } \\
\text { filled nylon } 6^{d}\end{array}$ \\
\hline Tensile strength & $\mathrm{MPa}$ & 97 & 76 & 69 & 67 \\
\hline Elongation at break & $\%$ & 7.75 & 11 & $3-4$ & 2.9 \\
\hline Flexural strength & MPa & 139 & 118 & 110 & 109 \\
\hline Flexural modulus & $\mathrm{GPa}$ & 3.6 & 3.14 & 3.792 & 3.4 \\
\hline Specific flexural strength & $\operatorname{MPa}\left(\mathrm{gcm}^{-3}\right)^{-1}$ & 119 & 101 & 85.94 & - \\
\hline Specific flexural modulus & $\mathrm{GPa}\left(\mathrm{gcm}^{-3}\right)^{-1}$ & 3.08 & 2.7 & 2.96 & - \\
\hline Impact strength & $\mathrm{J} \mathrm{m}^{-1}$ & 32 & 50 & 43 & 100 \\
\hline Density & $\mathrm{g} \mathrm{cm}^{-3}$ & 1.165 & 1.165 & 1.28 & - \\
\hline
\end{tabular}

ENR that the elongation is improved (Fig. 11). However, this increase is limited and not significant when compared to that of the neat nylon because of the presence of biocarbons within the nylon matrix, acting to restrict chain mobility.

Bench marking against natural fiber reinforced nylon 6 and commercially available mineral filled nylon 6 composites. In order to evaluate the potential of the biocomposites for applications especially requiring high strength to weight ratios, it has been bench marked against a commercially available mineral filled nylon 6 at the same weight concentrations. Table 3 lists the mechanical properties of NB, NBE3, APV3 and RTP 225 A. APV3 is a $20 \mathrm{wt} \%$ short fiber curaua reinforced nylon 6 biocomposite with the data extracted from Santos et al. ${ }^{34}$ RTP $225 \mathrm{~A}$ is a commercially available $20 \mathrm{wt} \%$ mineral filled nylon 6 used in the automotive industry and produced by RTP Co., USA. The mechanical properties of RTP 225 A were extracted from the company's datasheet. ${ }^{35}$ It can be observed that the tensile, flexural and impact strengths of NB and NBE3 are significantly better than those of RTP 225 A and APV3 with the exception of the impact strength of APV3 which is significantly higher. Likewise, the elongation at break is comparable. However, the stiffness of RTP 225 A and APV3 are better than those of NB and NBE3 due to the greater stiffness of the mineral component and fiber aspect ratio of the curaua fibers. The density of the biocomposites is one of its greatest advantages. It is significantly lower than that of RTP 225 A. Light weighting is a very important factor especially in the automotive industry. Therefore, the specific tensile and flexural properties were calculated based on the data obtained for NB, NBE3 and RTP 225 A. The results of the specific strength and moduli show that the biocomposites are superior to the RTP 225 A in terms of mechanical properties and have the potential to be utilized in automotive applications. Overall, the advantage of the biocomposites over mineral filled and natural fiber reinforced nylon composites is its tensile and flexural strengths and specific tensile and flexural properties as well. For automotive applications where moderate ratio of stiffness to toughness, high strengths and low density are required, the biocomposites have the potential to compete with currently used and commercially available composites.

\section{Water absorption}

The water absorption of the composites was tested and the results showed very interesting behaviors. There was little to no difference between the neat nylon and the composites at equilibrium. It was expected that the presence of a hydrophobic phase (ENR) dispersed within the hydrophilic phase (nylon) and the encapsulation of the biocarbon by the ENR will drastically reduce the water uptake. However, the contrary is observed when the curves of the equilibrium water uptake region are magnified (Fig. 12). As observed, there is an erratic decrease and increase of the curves of all the samples at the equilibrium region. This is due to sorption and desorption which occurs at very minute levels when equilibrium is reached. We observe a trend; NBE7 showed the highest water uptake and decreases with reduction in the ENR content followed by NB then neat nylon. If a trend line was to be fitted to the curve, it will show clearer difference between the samples. This behavior can be attributed to the presence of hydroxyl groups which were

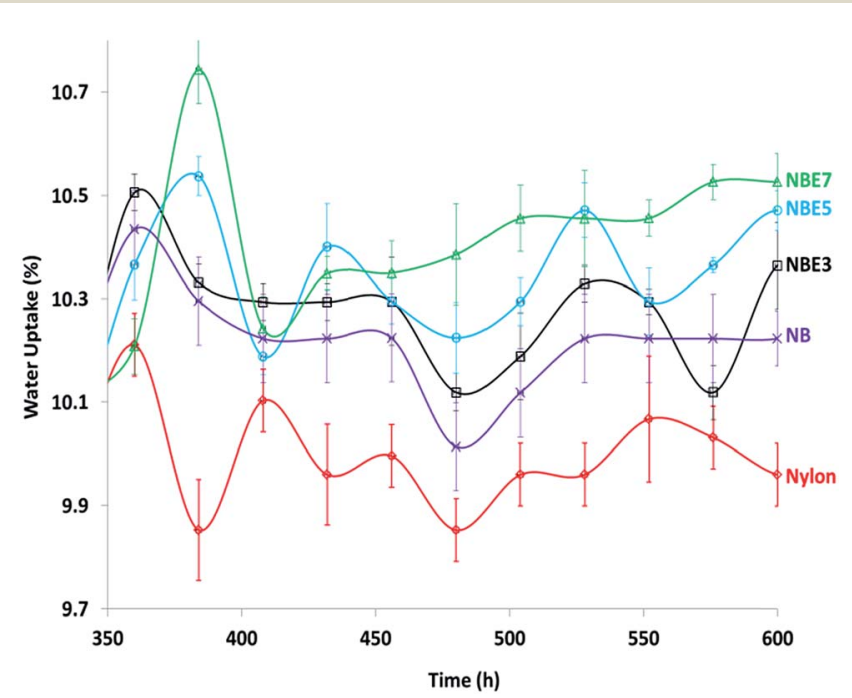

Fig. 12 Expanded equilibrium region of the water uptake of nylon 6 and its composites. 
formed from the formation of esters through the reaction of epoxide and carboxylic groups. With increase in the ENR content, there is an increase in the formation of esters which also produce hydroxyl groups as by products. It is well known that hydroxyl groups are highly hydrophilic and bond to water molecules very easily hence resulting in slightly higher water uptake than neat nylon and NB.

\section{Conclusion}

The study of the reinforcing and impact modifying effects of biocarbon and ENR, respectively, on nylon showed behaviors which were directly related to the microstructure formations of the composites as observed from the morphological properties and ENR and nylon. It was shown that the chemical interactions between ENR and biocarbon resulted to the encapsulation of the biocarbon by the ENR while also being dispersed in the nylon. FTIR confirmed the interactions between ENR-biocarbon and ENR-nylon by the presence of new peaks which were attributed to the $\mathrm{C}=\mathrm{O}$ vibration from the formation of ester groups from the interactions between epoxide groups on the ENR and carboxylic groups on the nylon and biocarbon. These resulted to drastic improvements in the impact strength of the composites when compared to that of $\mathrm{NB}$ at relatively low concentrations of ENR. The interactions between the biocarbon and nylon also resulted to good interfaces and increased tensile and flexural properties. The formation of an interface phase (ENR-g-nylon) was suggested to play an intrinsic role in the thermal properties such as the improvements in the glass transition temperatures of the ENR and nylon. The use of biocarbon and ENR to reinforce and modify the impact property of nylon respectively, showed a synergistic effect resulting to wellbalanced properties. Based on the stiffness-strength-toughness balance in comparison to the other impact modified biocomposites and bench marking against commercially available mineral filled nylon 6 (RTP 225 A) used in the automotive industry, biocarbon reinforced nylon 6 using 3 phr of ENR provides the best or optimum balance of mechanical properties within the concentrations studied in this work. The properties are either superior or equal to those of the neat nylon 6 and RTP $225 \mathrm{~A}$. It is believed that knowledge gained from this work can be used to further explore and engineer biocomposites derived from biocarbons geared towards automotive applications especially.

\section{Acknowledgements}

The authors acknowledge the financial support by the Ontario Ministry of Agriculture, Food and Rural Affairs (OMAFRA) University of Guelph Product Development and Enhancement through Value Chains Research Theme (Project \# 200399), the Natural Sciences and Engineering Research Council of Canada (NSERC) (Project \# 401111) and Ontario Research Fund, Research Excellence Program; Round-7 (ORF-RE07) from the Ontario Ministry of Research and Innovation (MRI), currently known as the Ontario Ministry of Research, Innovation and Science (MRIS) (Project \# 052644 and \# 052665).

\section{References}

1 D. Laura, H. Keskkula, J. Barlow and D. Paul, Effect of rubber particle size and rubber type on the mechanical properties of glass fiber reinforced, rubber-toughened nylon 6, Polymer, 2003, 44, 3347-3361.

2 D. Laura, H. Keskkula, J. Barlow and D. Paul, Effect of glass fiber surface chemistry on the mechanical properties of glass fiber reinforced, rubber-toughened nylon 6, Polymer, 2002, 43, 4673-4687.

3 S. Tjong, Short glass fiber-reinforced polyamide 6,6 composites toughened with maleated SEBS, Compos. Sci. Technol., 2002, 62, 2017-2027.

4 M. G. Segatelli, I. V. P. Yoshida and M. D. C. Gonçalves, Natural silica fiber as reinforcing filler of nylon 6, Composites, Part B, 2010, 41, 98-105.

5 B. Xie, M. Yang, S. Li, Z. Li and J. Feng, Studies on polyamide6/polyolefin blend system compatibilized with epoxidized natural rubber, J. Appl. Polym. Sci., 2003, 88, 398-403.

6 M. Narathichat, C. Kummerlöwe, N. Vennemann and C. Nakason, Thermoplastic natural rubber based on polyamide-12: influence of blending technique and type of rubber on temperature scanning stress relaxation and other related properties, J. Appl. Polym. Sci., 2011, 121, 805814.

7 M. Narathichat, C. Kummerlöwe, N. Vennemann, K. Sahakaro and C. Nakason, Influence of epoxide level and reactive blending on properties of epoxidized natural rubber and nylon-12 blends, Adv. Polym. Technol., 2012, 31, 118-129.

8 H. Nouparvar, A. Hassan, Z. Mohamad, M. U. Wahit and F. Roozbahani, The effect of organoclay contents on morphological characterization, mechanical and thermal properties of epoxidized natural rubber-50 toughened polyamide 6 nanocomposites, J. Polym. Eng., 2014, 34, 59-68.

9 J. Jancar and A. Dibenedetto, Effect of morphology on the behaviour of ternary composites of polypropylene with inorganic fillers and elastomer inclusions, J. Mater. Sci., 1995, 311, 1601-1608.

10 C. G. Ma, M. Q. Zhang and M. Z. Rong, Morphology prediction of ternary polypropylene composites containing elastomer and calcium carbonate nanoparticles filler, $J$. Appl. Polym. Sci., 2007, 103, 1578-1584.

11 P. R. Hornsby and K. Premphet, Influence of phase microstructure on the mechanical properties of ternary phase polypropylene composites, J. Appl. Polym. Sci., 1998, 70, 587-597.

12 H. Nouparvar, A. Hassan, Z. Mohamad and M. U. Wahit, Epoxidized natural rubber-50 toughened polyamide 6 nanocomposites: the effect of epoxidized natural rubber-50 contents on morphological characterization, mechanical and thermal properties, J. Elastomers Plast., 2012, 46, 269-283.

13 N. F. A. Sharif, Z. Mohamad, A. Hassan and M. U. Wahit, Novel epoxidized natural rubber toughened polyamide 6/ halloysite nanotubes nanocomposites, J. Polym. Res., 2011, 19, 9749. 
14 A. Mohanty, M. Misra and L. Drzal, Natural fibers, biopolymers, and biocomposites, 2005.

$15 \mathrm{X}$. Cao and W. Harris, Properties of dairy-manure-derived biochar pertinent to its potential use in remediation, Bioresour. Technol., 2010, 101, 5222-5228.

16 A. K. Mohanty, S. Vivekanandhan, A. Anstey and M. Misra, Sustainable Composites From Renewable Biochar And Engineering Plastic, in: 20th International Conference on Composite Materials, Copenhagen, 2015.

17 T. Huber, M. Misra and A. K. Mohanty, Biochar and its Size Effects on Polyamide 6/Biochar Composites, in: Proceedings of The American Society for Composites, 2015.

18 E. O. Ogunsona, M. Misra and A. K. Mohanty, Sustainable biocomposites from biobased polyamide 6,10 and biocarbon from pyrolyzed Miscanthus fibers, J. Appl. Polym. Sci., 2016, 134, 44221.

19 E. Behazin, E. Ogunsona, A. Rodriguez-Uribe, A. K. Mohanty, M. Misra and A. O. Anyia, Mechanical, Chemical, and Physical Properties of Wood and Perennial Grass Biochars for Possible Composite Application, BioResources, 2016, 11, 1334-1348.

20 A. K. Manna, P. P. De, D. K. Tripathy, S. K. De and M. K. Chatterjee, Chemical Interaction between Surface Oxidized Carbon Black and Epoxidized Natural Rubber, Rubber Chem. Technol., 1997, 70, 624-633.

$21 \mathrm{~S}$. Ahmed and F. Jones, A review of particulate reinforcement theories for polymer composites, J. Mater. Sci., 1990, 25, 4933-4942.

22 C. S. L. Baker, I. R. Gelling and R. Newell, Epoxidized Natural Rubber, Rubber Chem. Technol., 1985, 58, 67-85.

23 T.-C. Li, J. Ma, M. Wang, W. C. Tjiu, T. Liu and W. Huang, Effect of clay addition on the morphology and thermal behavior of polyamide 6, J. Appl. Polym. Sci., 2007, 103, 1191-1199.

24 N. S. Murthy, Hydrogen bonding, mobility, and structural transitions in aliphatic polyamides, J. Polym. Sci., Part B: Polym. Phys., 2006, 44, 1763-1782.

25 J. Jiang, D. Zhang, Y. Zhang, K. Zhang and G. Wu, Influences of Carbon Nanotube Networking on the Conductive, Crystallization, and Thermal Expansion Behaviors of
PA610-Based Nanocomposites, J. Macromol. Sci., Part B: Phys., 2013, 52, 910-923.

26 J. D. Menczel, L. Judovits, R. B. Prime, H. E. Bair, M. Reading and S. Swier, Differential Scanning Calorimetry (DSC), in: Thermal Analysis of Polymers, John Wiley \& Sons, Inc., 2008, pp. 7-239.

27 C. Nakason, M. Narathichat, C. Kummerlowe and N. Vennemann, Thermoplastic natural rubber based on polyamide-12 blended with various types of natural rubber: effect of processing oils and plasticizer, J. Elastomers Plast., 2012, 45, 47-75.

28 C. Komalan, Dynamic mechanical analysis of binary and ternary polymer blends based on nylon copolymer/EPDM rubber and EPM grafted maleic anhydride compatibilizer, eXPRESS Polym. Lett., 2007, 1, 641-653.

29 Z. You and D. Li, Highly filled bamboo charcoal powder reinforced ultra-high molecular weight polyethylene, Mater. Lett., 2014, 122, 121-124.

30 X. Li, B. Lei, Z. Lin, L. Huang, S. Tan and X. Cai, The utilization of bamboo charcoal enhances wood plastic composites with excellent mechanical and thermal properties, Mater. Des., 2014, 53, 419-424.

31 W. Gindl-Altmutter, C. Fürst, A. Raj Mahendran, M. Obersriebnig, G. Emsenhuber, M. Kluge, et al., Electrically conductive kraft lignin-based carbon filler for polymers, Carbon, 2015, 89, 161-168.

32 R. J. M. Borggreve, R. J. Gaymans and J. Schuijer, Impact behaviour of nylon-rubber blends: 5. Influence of the mechanical properties of the elastomer, Polymer, 1989, 30, 71-77.

33 S. Y. Hobbs, R. C. Bopp and V. H. Watkins, Toughened nylon resins, Polym. Eng. Sci., 1983, 23, 380-389.

34 P. A. Santos, M. A. S. Spinacé, K. K. G. Fermoselli and M.-A. De Paoli, Polyamide-6/vegetal fiber composite prepared by extrusion and injection molding, Composites, Part A, 2007, 38, 2404-2411.

35 RTP Co., Product Datasheet and General Processing Conditions RTP 225 A Nylon 6 (PA) Mineral, http:/web.rtpcompany.com/ info/data/0200A/RTP225A.htm, Extracted on 15th Nov, 2016. 